\title{
The Effect of Addition of Palm Oil Dry Waste Against Growth Rate of Sawi Plant (Brassica rapa) On Learning Environmental Knowledge
}

\author{
Edi Azwar \\ Faculty of Teacher Training and Education, North Sumatera Islamic University, Medan, 20217, Indonesia \\ ediazwar@fkip.uisu.ac.id \\ * Corresponding Author \\ Whatsapp Number [+62812636780]
}

How to Cite : Azwar E. (2020). The Effect of Addition of Palm Oil Dry Waste Against Growth Rate of Sawi Plant (Brassica rapa) On Learning Environmental Knowledge. International Journal for Educational and Vocational Studies, 2 (8), 731-736. DOI: https://doi.org/10.29103/ijevs.v2i8.2762

\section{ARTICLE HISTORY}

Received: 2 June 2020

Revised: 11 July 2020

Accepted: 24 July 2020

KEYWORDS

Sludge;

Growth Rate;

Environmental Knowledge;

Palm Oil Dry Waste;

\section{ABSTRACT}

The Utilization of sludge oil palm processing plant is still not optimal, therefore it is necessary to study the use of sludge as an alternative supply of nutrients in the soil that is used as an additional planting medium. This research contributes to environmental knowledge courses according to the syllabus and RPS and the output products of this study are learning modules. This study aims to determine the effect of the addition of palm oil dry mud waste to the growth rate of mustard plants (Brassica rapa) on the study of Environmental Knowledge, and to compile the module as the development of teaching materials from the Environmental Knowledge course module. This study used a completely randomized design with six treatments and four replications. The results of this study can be concluded that the administration of sludge is very influential in increasing nutrient and growth of mustard plants, namely: plant height $(\mathrm{cm})$, leaf surface area $(\mathrm{cm} 2)$, number of leaf strands, and stem length (cm).

\section{INTRODUCTION}

Palm oil is one of the largest plantation commodities in Indonesia. The development of land area and palm oil production increases every year. According to the Directorate General of Forestry (2014) the development of palm oil continues to increase every year as seen from the average rate of growth of the area of oil palm during 2004-2014 of $7.67 \%$, an area of 10.9 million ha with a production of 29.3 million tons of Curde Palm Oil (CPO). Palm oil mills process palm oil into Curde Palm Oil (CPO) and Palm kernel, in addition to that also produced $75 \%$ of solid waste and liquid waste. Solid waste is in the form of empty bunches, shells and fibers, while liquid waste produced in the form of sludge. According to Wahyono et al., (2008) sludge is a suspension of liquid waste suspension and microorganisms in it originating from sewage treatment in wastewater treatment plants. Along with technological advances and environmental concerns, waste treatment is very important to prevent environmental damage and to preserve the environment (Jenny, 1999). One of the actions that can be taken is to - utilize palm oil mill solid waste as an addition to the amount of nutrients in the soil and to make the planting media of a plant that has economic value. If the waste is not produced or treated properly, it will pollute the environment around the plant. 2050 is predicted to be the main cause of death due to environmental pollution (OECD, 2012), so knowledge of the environment must be an inseparable part of the world of education. In environmental science also discusses environmental problems caused by factory waste, one of which. Which a certain amount of waste can still be recycled by nature. Will be fixed, if the number increases so that there is something left behind and cannot be recycled then it will become a polluter. This research contributes to the Environmental Knowledge course in accordance with the Syllabus and RPS and the output products of this study are learning modules, which later the product can be used as learning tools. One of the plants that has economic value is ginger, mustard greens, tomatoes, and celery. But the plants that will be used for research are mustard plants. Mustard is a vegetable that is loved by all groups 
of people. Demand for mustard plants always increases with increasing population and awareness of nutritional needs. (Haryanto et al., 2006). The economically valuable part of mustard plants is leaves, so efforts to increase production are sought at increasing vegetative products, so as to support these efforts fertilization is carried out. Mustard plants require sufficient nutrients and are available for growth and development to produce maximum production. Therefore, researchers want to use oil palm sludge as a planting medium.

\section{RESEARCH METHOD}

\subsection{Research Location, Materials and Tools}

\section{Research Location}

The location of this research was conducted in the area of Biology Education Study Program FKIP UISU.

\section{Materials and Tools}

The research was carried out by preparing tools and materials, then carried out by seeding mustard seedlings in a bucket that had been given soil, the seeding process lasted for 7 days, then determine the planting pattern. After sowing the mustard seedlings are transferred into a polybag that has been given sewage sludge. After being transferred, watering is done every 2 times a day (morning and evening)

\subsection{Population and research time}

\section{Population}

The population in this study is the Brassica rappa mustard plant group which is grouped into several treatments at different times at regular intervals.

\section{Research Time}

The The time of this research was in May-June 2019.

\subsection{Research Design, Work Procedures,and Observations}

This study used a completely randomized design method with 6 treatments and 4 replications, namely: $\mathrm{P} 0=$ CONTROL, P1 $=(50 \% \mathrm{LS}+50 \% \mathrm{LAND}), \mathrm{P} 2=(60 \% \mathrm{LS}+40 \%$
LAND), $\mathrm{P} 3=(70 \% \mathrm{LS}+30 \% \mathrm{LAND}), \mathrm{P} 4=(80 \% \mathrm{LS}+20 \%$ LAND), P5 = (90\% LS + 10\% LAND).

\subsection{Data Analysis Techniques}

Data collection is done once every 7 days by measuring the parameters of plant height $(\mathrm{cm})$, stem length $(\mathrm{cm})$, number of leaves (strands), and leaf surface area $\left(\mathrm{cm}^{2}\right)$.

Information:

\section{LS = Sludge Waste}

\section{RESULTS AND DISCUSSION}

The provision of palm oil dry sludge (sludge) can significantly increase the growth of mustard plants (Brassica rapa), such as: plant height, stem length, number of leaves, and leaf surface area shown in Table Provision of oil palm sludge waste can increase the growth of mustard plants (Brassica rapa). This can be seen from the increase in plant height, stem length, number of leaves, and leaf surface area. This increase shows a statistically significant difference, and the increase in plant growth is indirectly affected by the provision of palm oil dry sludge containing nutrients that can be used by plants to grow optimally. As mentioned in Jenny and Sawadji (1999), indirectly the waste of dry oil palm sludge can increase soil fertility. Together with soil minerals, the dry sludge material applied has an effect on a number of soil chemical activities. Growth of plant height, stem length, number of leaf blades, and leaf surface area in mustard plants (Brassica rapa) were clearly visible at the age of $3 \mathrm{MST}$, the growth of each of each parameter increased significantly, this was due to nutrients contained in the mud Dry palm oil is available for plants which further stimulates the growth of plants and nutrients derived from waste oil palm dry mud, especially $\mathrm{K}$ is able to increase the availability of $\mathrm{K}$ soil. The percentage increase in treatment was due to the addition of dry mud waste to the soil. The results of the analysis showed that the average plant height, stem length, number of leaf strands, and leaf surface area were highest in the P5 treatment (90\% dry mud waste $+10 \%$ soil) compared to the other treatments. Provision of dry sludge can increase nutrients, namely $\mathrm{N}, \mathrm{P}, \mathrm{K}$. This can be seen in table 1 .

Table 1. Combined Analysis of Each Parameter

\begin{tabular}{|c|c|c|c|c|}
\hline \multirow[b]{2}{*}{ Treatment } & \multicolumn{2}{|c|}{ Leaf } & \multirow{2}{*}{$\begin{array}{l}\text { Length of the stem } \\
\qquad \mathrm{cm}\end{array}$} & \multirow{2}{*}{$\begin{array}{c}\text { Plant Height } \\
\mathrm{cm}\end{array}$} \\
\hline & Number of leaves & $\begin{array}{l}\text { Leaf Surface area } \\
\mathrm{cm}\end{array}$ & & \\
\hline P0 & 6 & 6,60 & 9,34 & 47,06 \\
\hline $\mathrm{P} 1$ & 7 & 10,35 & 11.91 & 64,13 \\
\hline $\mathrm{P} 2$ & 7 & 11.08 & 12,70 & 64,92 \\
\hline P3 & 8 & 12,21 & 13,60 & 66,02 \\
\hline $\mathrm{P} 4$ & 9 & 12,98 & 14,63 & 69,11 \\
\hline $\mathrm{P} 5$ & 10 & 14,42 & 15,95 & 73,36 \\
\hline
\end{tabular}


Table 2. Treatment 1

\begin{tabular}{|c|c|c|c|c|c|}
\hline Treatment & 1 MST & 2 MST & 3 MST & Total & 47.06 \\
\hline $\mathrm{p} 0$ & 9.75 & 12.88 & 24.43 & 64.13 & 21.37667 \\
\hline $\mathrm{p} 1$ & 10.25 & 18.08 & 35.8 & 56.84 & 18.94667 \\
\hline $\mathrm{p} 2$ & 8.23 & 15.53 & 33.08 & 48.83 & 16.27667 \\
\hline $\mathrm{p} 3$ & 8.08 & 15.6 & 25.15 & 47.98 & 15.99333 \\
\hline $\mathrm{p} 4$ & 8.2 & 15.68 & 24.1 & 57.36 & 19.12 \\
\hline $\mathrm{p} 5$ & 8.25 & 15.68 & 33.43 & 322.2 & 17.9 \\
\hline Total & 52.76 & 93.45 & 175.99 & & \\
\hline
\end{tabular}

Plant height at the age of 1 MST, 2 MST and 3 MST showed a significant effect between each treatment. At the age of 1 MST plant height was not very visible difference, but when 2 MST had been fertilized using NPK plant height began to notice a difference between P0 (CONTROL) and mixed with dry sludge. It can be seen in Figure 2, mustard that is planted using additional sludge is seen higher than mustard that is only planted using soil. After the age of 3 MST, the height of the meeting plants increased, but there were two plants namely P3B and P4B that died due to caterpillars that ate mustard buds and poultry disorders such as chickens also ate the mustard leaves. The percentage increase in treatment was due to the addition of dry mud waste to the soil and because of the influence of NPK fertilizer.

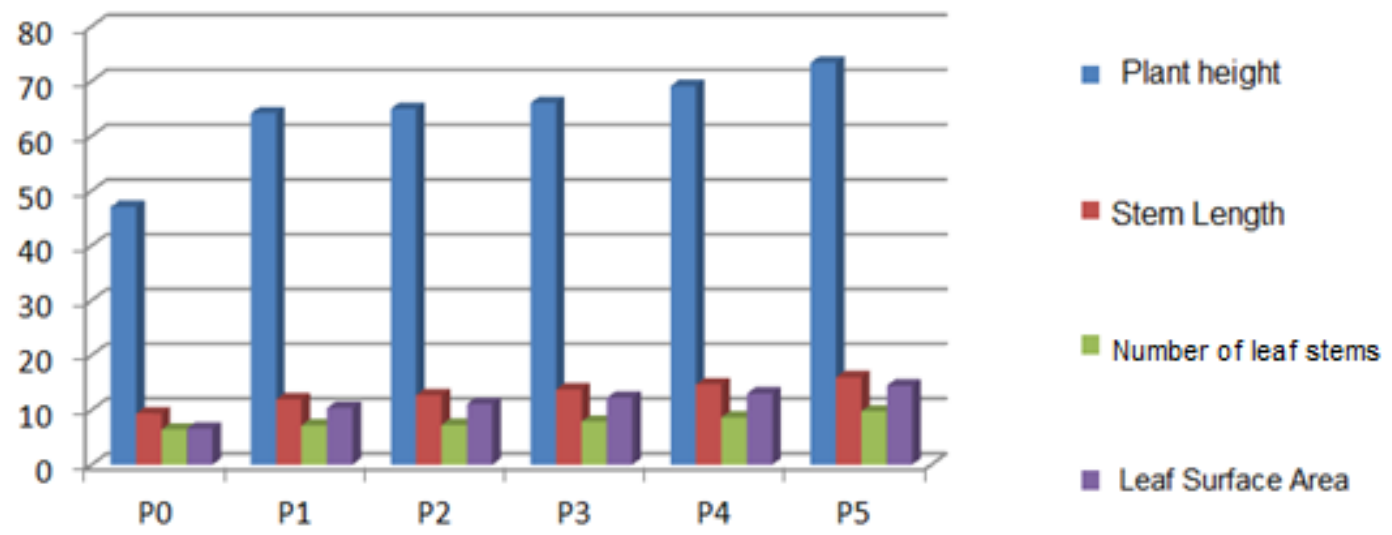

Figure 1. Draw Bar Graphic W the Number of Comparisons Between Repetition and Number of Larval Deaths After 6 Hours

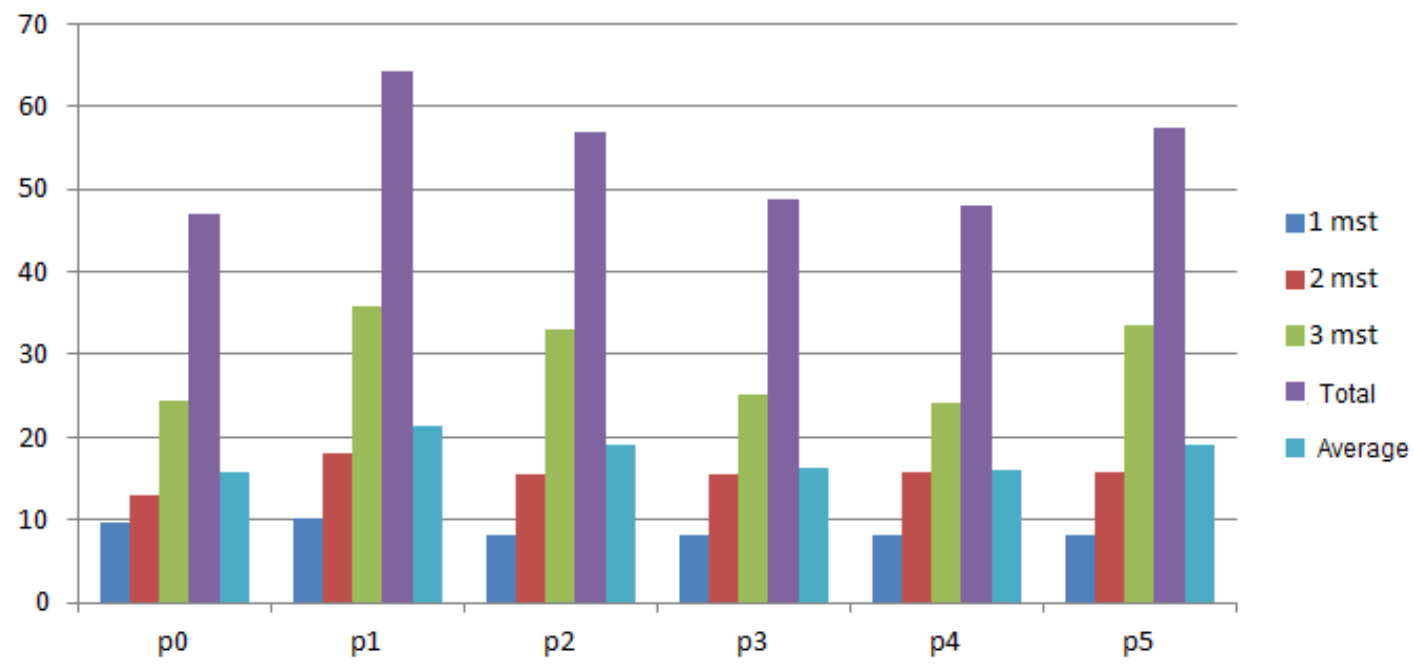

Figure 2. Draw Bar Graphic of Plant Height Aftert all Comparison 


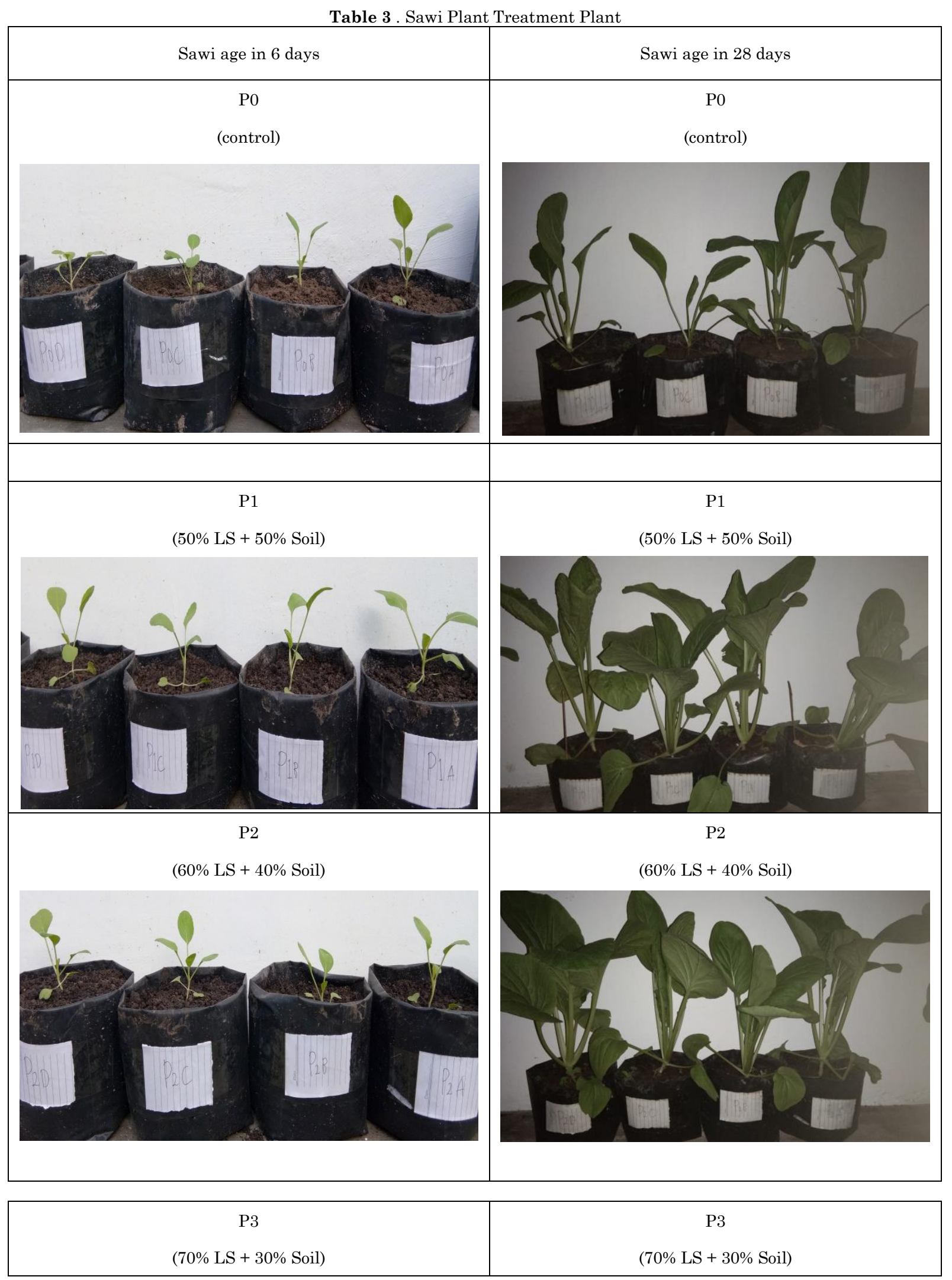




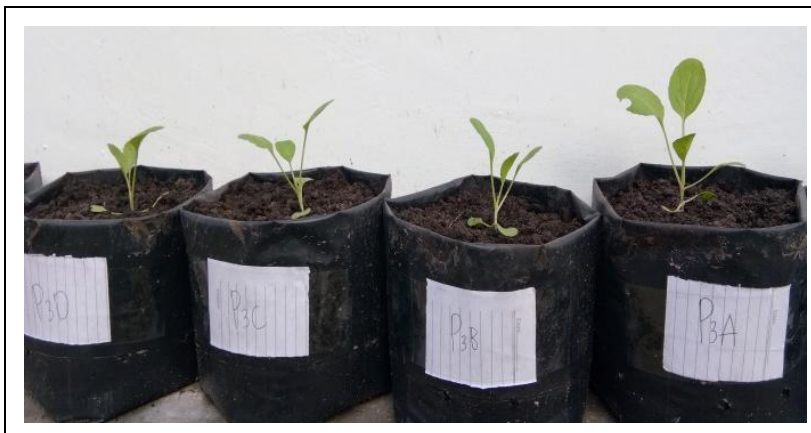

$\mathrm{P} 4$

$(80 \%$ LS $+20 \%$ Soil $)$

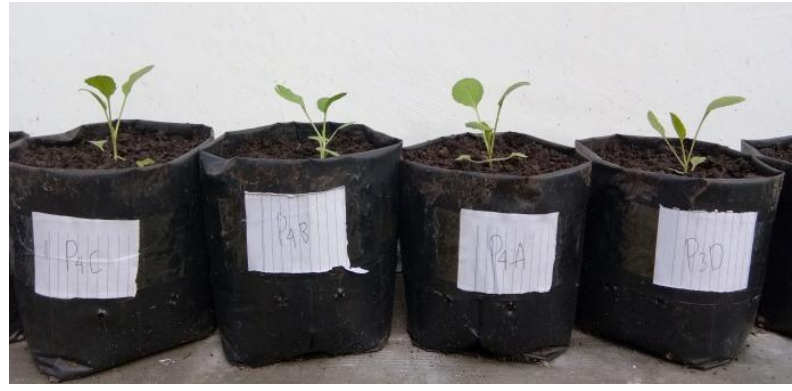

P5

$(90 \% \mathrm{LS}+10 \%$ Soil $)$

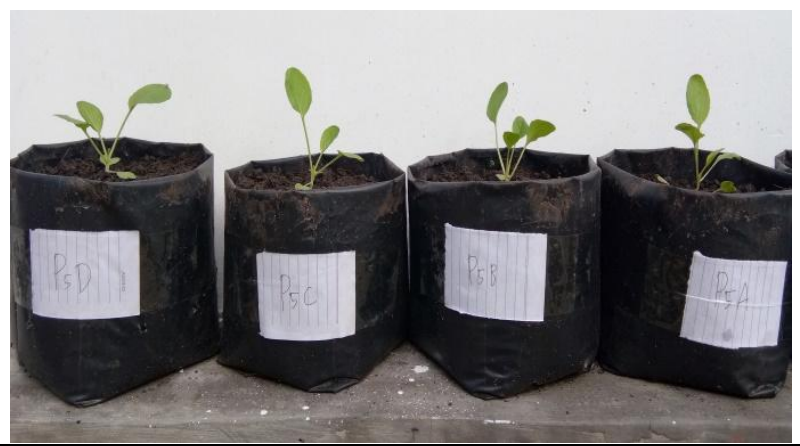

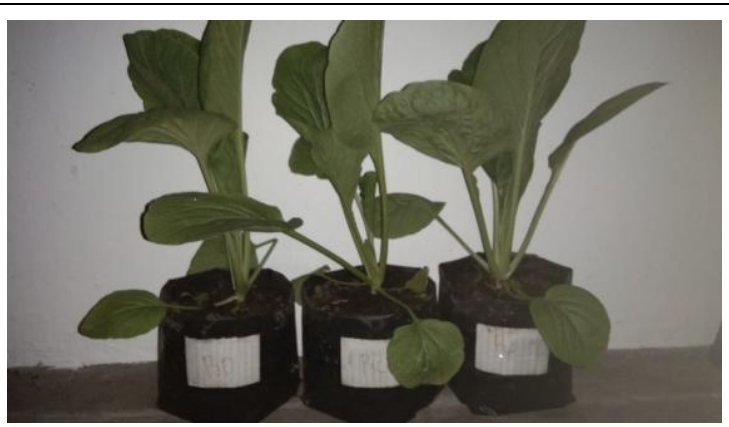

$\mathrm{P} 4$

$(80 \%$ LS + 20\% Soil)

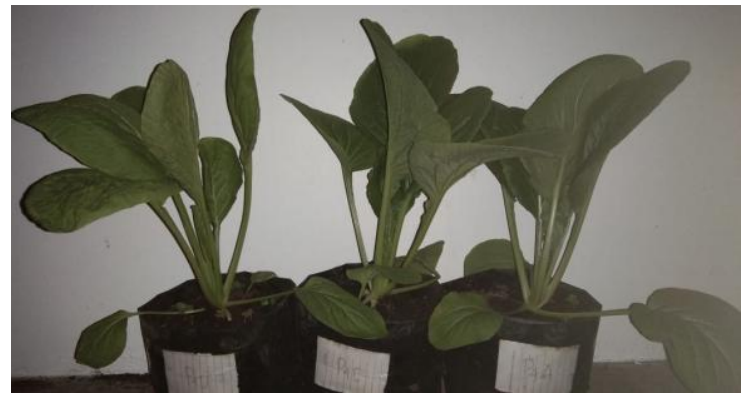

P5

$(90 \% \mathrm{LS}+10 \%$ Soil $)$

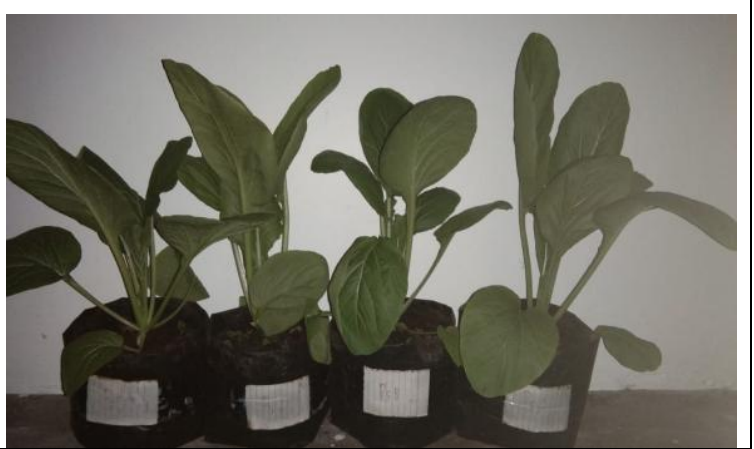

\section{RESULT OBSERVATION}

Plant growth from sprouts to adulthood is largely influenced by organic matter. Plant remnants returned to the soil create conditions that stimulate seed germination. After the organic material has decayed the nutrients and acids released greatly affect subsequent plant growth (Kononova, 1966). According to Sutedjo (2010), if the N element needs are fulfilled, it can increase plant growth. As is known the element N contained in NPK fertilizer, serves to increase leaf growth so that the leaves will become many in number and will become wider with a greener color that will increase protein levels in the plant body.

\section{CONCLUSION}

Giving palm oil dry sludge waste can increase nutrient substances and other contents such as N, P, and K. Giving palm oil dry sludge waste (sludge) can increase the growth of mustard plants (Brassica rapa) significantly, such as: plant height, length stems, number of leaves, and leaf surface area. All parameters showed significant values in the treatment P5 $=(90 \% \mathrm{LS}+10 \%$ LAND $)$. It can be concluded that the more addition of palm oil dry mud waste, the higher the value that will be obtained.

\section{REFERENCES}

PDitjenbun. (2014). Palm Oil Growth Increases. Accessed from (http://ditjenbun.pertanian.go.id) on March 20, 2019.

Wahyono, et al, (2008). Evaluation of Palm Oil Industry Solid Waste Handling Technology. Proceedings of the Technology Seminar for the Country, B 151.

Jenny, M.U and E. Suwadji. (1999). Utilization of Palm Oil Waste (Sludge) as Plant Fertilizer and Wood Mushroom Media. BATAN, Bogor. 
Haryanto, et al. (2006). Mustard and Lettuce. Self-help Spreaders. Jakarta. 112

Kononova, M. M. (1966). Organic Matter Soil. Persemon Press. London

Sutedjo, M. (2010). Fertilizers and Fertilizing Methods. Jakarta: Rineka Cipta. 